\title{
New Clinical Insights into Chronic Obstructive Pulmonary Disease and Their Implications for Pharmacoeconomic Analyses
}

\author{
Douglas W. Mapel and Melissa H. Roberts \\ Lovelace Clinic Foundation, Albuquerque, NM, USA
}

\section{Contents}

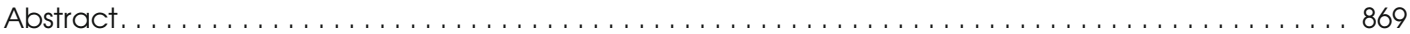

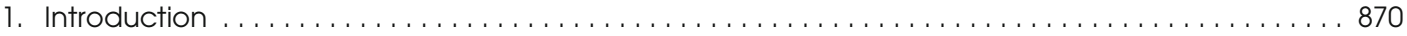

2. Chronic Obstructive Pulmonary Disease (COPD): Costs and Perspective . . . . . . . . . . . . . . . 872

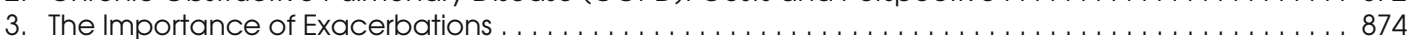

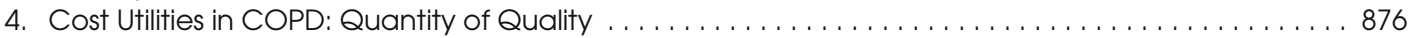

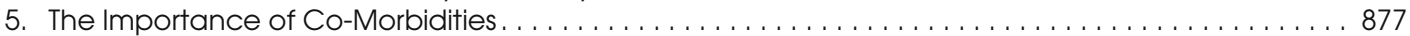

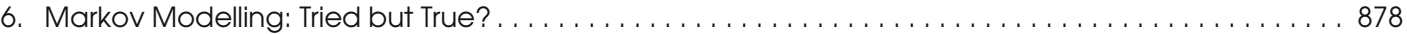

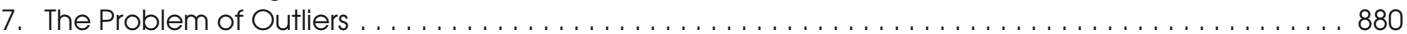

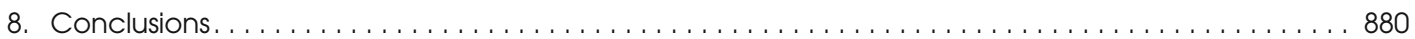

\section{Abstract}

Chronic obstructive pulmonary disease (COPD) is one of the leading causes of death and disability worldwide, but before the development of several new pharmacological treatments little could be done for COPD patients. Recognition that these new treatments could significantly improve the prognosis for COPD patients has radically changed clinical management guidelines from a palliative philosophy to an aggressive approach intended to reduce chronic symptoms, improve quality of life and prolong survival. These new treatments have also sparked interest in COPD cost-effectiveness research. Most COPD cost-effectiveness studies have been based on clinical trial populations, limited to direct medical costs, and used standard analysis methods such as Markov modelling, and they have usually found that newer therapies have favourable cost effectiveness. However, new insights into the clinical progression of COPD bring into question some of the assumptions underlying older analyses.

In this review, we examine clinical factors unique to COPD and recent changes in clinical perspectives that have important implications for pharmacoeconomic analyses. The main parameters explored include (i) the high indirect medical costs for COPD and their relevance in assessing the societal benefits of new therapy; (ii) the importance of acute deteriorations in COPD, known as exacerbations, and approaches to modelling the cost benefit of exacerbation reduction; (iii) quality/utility instruments for COPD; (iv) the 
prevalence of co-morbid conditions and confounding between COPD and co-morbid disease utilization; (v) the limitations of Markov modelling; and (vi) the problem of outliers.

\section{Key points for decision makers}

- Concepts about the progression and treatment of chronic obstructive pulmonary disease (COPD) have substantially changed over the last two decades, with several implications for the design of pharmacoeconomic studies

- Indirect medical costs are often overlooked in COPD cost analyses, but the available data suggest that treatment benefits may be substantial for the growing number of working-age COPD patients

- COPD exacerbations have a great impact on healthcare utilization, so the success of cost models is largely related to their ability to describe exacerbation-related costs

- Micro-simulation and discrete-event models may have unique advantages over Markov models in describing COPD progression

\section{Introduction}

Chronic obstructive pulmonary disease (COPD) is the variable combination of emphysema and chronic bronchitis, both of which are caused by an enhanced chronic inflammatory response to cigarette smoke and other inhaled noxious particulates and gases; both result in persistent expiratory airflow limitation that can be confirmed by spirometry. Symptoms caused by COPD include shortness of breath with exertion, wheezing and chronic cough. These symptoms are insidiously progressive but punctuated by episodes of acute worsening known as exacerbations. The WHO estimates that more than 3 million people die from COPD every year, which is $5 \%$ of all deaths globally, and in the US COPD is now the third most common cause of death. ${ }^{[1-4]}$ Although most people diagnosed with COPD are age 65 years and older, it is not uncommon among middle-aged adults and thus is a leading cause of work disability in most industrial nations. ${ }^{[5-8]}$

COPD has a substantial impact on healthcare utilization and costs. Results from the Confronting COPD in North America and Europe study, an international survey conducted in seven countries (Canada, France, Italy, the Netherlands, Spain, the UK and the US), showed that for six of the seven countries, hospitalizations for COPD per 100 individuals ranged from 27 to 43 (for the seventh country there was on average one hospitalization per person) and emergency department visits ranged on average for five of the seven countries from 33 to 78 per 100 (and from 10 to 15 for the other two); for five of the seven countries, hospitalizations accounted for 52-84\% of direct COPD healthcare costs. ${ }^{[9]}$ Indirect costs varied across countries, but were found to account for a significant portion of the societal costs of COPD in Canada, France, the UK and the US. ${ }^{[9]}$ Direct and societal costs were highest in the US, and the US also had the highest percentage of individuals reporting lost productivity due to COPD. ${ }^{[9]}$ Chronic respiratory diseases are among the top five reasons for outpatient clinic and emergency department visits, ${ }^{[10]}$ and are also among the top ten costliest conditions in the US. ${ }^{[1]}$ In 2009, associated costs in the US from chronic respiratory diseases were forecast to reach \$US49.9 billion in 2010, including \$US29.5 billion in direct medical cost, \$US8 billion due to morbidity and \$US12.4 billion due to mortality, with the composition of direct costs being $44.7 \%$ hospital care, $18.6 \%$ physician services, $19.7 \%$ prescription drugs, $4.4 \%$ home healthcare and $12.5 \%$ nursing home care. ${ }^{[1]}$ 
Even though COPD has a tremendous impact on morbidity, mortality and healthcare cost, until recently there was relatively little published on treatment cost effectiveness. That is largely due to the fact that treatment options were very limited and little could be done to affect the long-term outcome of this disease other than to give supplemental oxygen to those in its terminal stages. Over the last decade new pharmaceutical treatments have been developed that improve the long-term prognosis for COPD patients while also reducing their day-to-day respiratory symptoms and improving their quality of life (QOL). This has brought a fundamental change in treatment philosophy from a palliative approach to an aggressive interventional strategy with the goals of improving overall functional status, reducing respiratory symptoms, reducing risk of acute exacerbation events, and providing a longer and healthier life. ${ }^{[12]}$

As pharmaceutical treatment options have increased for COPD, so has interest in treatment cost effectiveness, partly due to increased funding of studies from pharmaceutical companies. We reviewed the US National Library of Medicine PubMed database and the Tufts Cost-Effectiveness Analysis Registry, and found that as of February 2012 there were approximately 76 cost-effectiveness studies of COPD pharmaceutical treatments that had been published since 1990 (see the appendix in the Supplemental Digital Content [SDC], http:// links.adisonline.com/PCZ/A155). Approximately half of the studies were based on observational data, one-quarter were based on randomized controlled trials (RCTs) and the remaining one-quarter were modelling studies. The important role RCT studies have in providing evidence of treatment safety, efficacy and effectiveness is well known. Modelling studies, however, have a unique role in that they allow for further consideration of information from multiple studies, synthesizing information on factors relevant to disease treatment and outcomes, and allowing comparison of competing treatments across clinical, economic and humanistic outcomes. With regard to COPD, the predominant pharmacoeconomic model has been the cost-effectiveness analysis, a subgroup of which is the cost-utility analysis.
Prior to the year 2000 , there were only nine economic evaluations of specific COPD or chronic bronchitis drug treatments listed in MEDLINE. Molken and colleagues ${ }^{[13]}$ noted in their 1992 review that cost-effectiveness studies of COPD pharmacotherapy were found to be "totally lacking". Ruchlin and Dasbach ${ }^{[14]}$ reported findings from published studies from 1980 to 2000 , finding 15 economic evaluations of COPD pharmacotherapy (all but three of which were published in 1990 or later), but did not discuss methodological aspects of the studies.

Ramsey ${ }^{[15]}$ initiated discussion of critical evaluation of economic studies in 2000 and then with Sullivan ${ }^{[16]}$ provided a thorough examination based on the state of COPD therapy and economic evaluations as of 2002. Ramsey and Sullivan, ${ }^{[16]}$ in addition to emphasizing that model parameters should be clearly stated, discussed analysis issues related to cost distributions, the need for co-morbidity adjustment in analyses and inclusion of QOL outcomes. In 2006, D'Souza and colleagues ${ }^{[17]}$ published a review that examined seven studies of inhaled COPD maintenance treatments, focusing on how well they followed the Drummond 10-point checklist for critical assessment of pharmacoeconomic studies, ${ }^{[18]}$ five studies were based on RCTs and the other two were modelling studies. The main criticisms from this appraisal concerned the heterogeneity in study populations and definitions of outcomes, and the paucity of comparative analyses for relevant treatment strategies since the comparison group for all studies was placebo/usual care or ipratropium. ${ }^{[17]}$ Rutten-van Molken and Lee, ${ }^{[19]}$ also in 2006, published a brief overview of five Markov COPD progression models that had been published in 2004 and 2005, one of which had also been discussed by D'Souza and colleagues. ${ }^{[17]}$ All of the models incorporated a definition of COPD severity based on staging using American Thoracic Society percentage of predicted forced expiratory volume in 1 second $\left(\mathrm{FEV}_{1}\right)$ criteria. The main criticisms from Rutten-van Molken and Lee ${ }^{[19]}$ concerned the variation in model populations and utility and disease progression estimates as well as the ability of models to incorporate the impact of smoking and exacerbation rates on disease 
progression, noting that key priorities for future models should be better utility information and better definition of outcome measures.

Starkie and colleagues ${ }^{[20]}$ provided the most comprehensive review in their critical appraisal of 15 economic evaluations of COPD treatments published between 1990 and 2007, adding two more modelling studies, four RCTs and one observational study to those included in previous reviews. Of the five decision-analysis models included, only one utilized a societal perspective; one was published in 1993, the others in 2004-2006. Of the more recently published studies, three assessed QOL; however, health state utility values differed greatly between studies as did the duration of effect assigned to each exacerbation. ${ }^{[20]}$ Starkie and colleagues ${ }^{[20]}$ also emphasized that the internal and external validity of models was a major concern, as was the need for models to capture long-term effects of treatment. Ferdinands and Mannino ${ }^{[21]}$ reviewed methodologies for assessing validity in obstructive lung disease simulation models, five of which were COPD pharmaceutical treatment models that have been discussed in previous reviews. ${ }^{[22-26]}$ Ferdinands and Mannino ${ }^{[21]}$ were encouraged by the fact that almost all of the reviewed models incorporated some sort of validation review, although the methods used for assessing model validity were inconsistent across studies. It should be noted, however, that the most recent COPD model reviewed was published in 2006 and many of the recommendations regarding standard terminology and reporting of methodologies are not as relevant for more recent cost-effectiveness studies because of the emphasis pharmaceutical outcomes research professional organizations and journals have placed on ensuring published articles incorporate a comprehensive discussion of economic evaluation model assumptions and functionality. 27,28$]$

We were able to identify an additional 14 economic modelling evaluations for COPD published between 2006 and early 2012 (see SDC). ${ }^{[29-43]}$ Bases for the models were: Markov processes $(n=10)$, Monte Carlo simulations $(\mathrm{n}=3)$ and Latin hypercube simulations $(n=1)$. Staging by $\mathrm{FEV}_{1}$ was used to model disease progression and/or assess risk in nine of the models; ${ }^{[30-32,34-36,38,41-43]}$ ex- acerbation experience was considered in three models in assessing future outcomes. ${ }^{[29,39,40]}$

Almost all pharmacoeconomic COPD treatment models have been published in the last decade (2004 and later), and for the most part have been constructed around staging using percentage of predicted $\mathrm{FEV}_{1}$ criteria. In that time period several large randomized clinical trials and longitudinal cohort studies were completed that have not only expanded information about specific pharmacological benefits, but have also substantially altered treatment guidelines and fundamentally changed the way clinicians think about COPD.

In this review we discuss methodological issues that continue to be rarely addressed, as well as recent findings that have altered the clinical perspective of COPD and their important implications for pharmacoeconomic analyses of COPD treatments. An extensive list of references is provided to help illustrate these nuances of COPD economic research; however, this is not a systematic review of pharmacoeconomic studies. Rather, this is a discussion of important aspects of COPD economics that are not currently well examined in the literature, and how recent changes in treatments and guidelines may affect future analytic approaches.

\section{Chronic Obstructive Pulmonary Disease (COPD): Costs and Perspective}

Most COPD economic analyses have examined only direct medical cost (e.g. inpatient, outpatient and prescription pharmacy costs), written from the perspective of the payer or provider. In a 2006 review of 13 articles assessing the economic burden of COPD, Foster and colleagues ${ }^{[44]}$ found only two that included indirect costs. In the 14 articles we have reviewed since, we also found only two that included indirect costs. ${ }^{[31,36]}$ However, the available data obtained from 'top-down' approaches do suggest that in COPD these other costs are quite substantial. In the US, the National Heart, Lung, and Blood Institute estimates indirect cost for COPD at $44 \%$ of total costs, which is based largely on national expenditures for disability payments and long-term care. ${ }^{[4]}$ 
Chronic respiratory conditions are the fourth leading cause of disability among adults in the US, ${ }^{[45]}$ and result in over \$US6.35 billion of lost productivity each year. ${ }^{[46]}$ Systems for determining disability and the amounts of compensation vary widely among industrial nations, but most spend about $1 \%$ of their gross domestic product on direct disability payments, and the available data demonstrate that disability caused by COPD has a substantial societal impact on these countries. ${ }^{[47]}$

Studies that have used a patient-level approach are rare, but are consistent with national health expenditure data. The Confronting COPD Survey, which was based on structured interviews of thousands of COPD patients worldwide, estimated the average indirect costs among US participants at $27 \%$ of total societal costs. ${ }^{[48]}$ The European and Canadian surveys found that costs due to lost productivity ranged from $5 \%$ to $67 \%$ of the total societal costs, ${ }^{[9,49-54]}$ with variability among countries mostly due to the large differences among the demographic characteristics of the samples. The indirect costs varied dramatically with disease severity, increasing from 4 to 17 times from mild to severe stages. ${ }^{[9,54]}$ The Obstructive Lung Disease in Northern Sweden (OLIN) survey estimated the indirect costs to be $58 \%$ of the total costs. ${ }^{[55]}$ In the SIRIO (Social Impact of Respiratory Integrated Outcomes) study from Italy, a comprehensive assessment of 561 COPD patients that captured both direct and indirect costs, the total cohort lost 5703 work days over 1 year, an amount made more impressive by the fact that the mean age was 70.3 years and thus more than half were either retired or already on medical disability. ${ }^{[56]}$ Another international survey, focused on the societal impact of COPD among working-age adults in Brazil, China, Germany, Turkey, the UK and the US found that among the 2426 people who completed the survey, $40 \%$ had retired prematurely, resulting in an average loss in lifetime income of \$US316000 (adjusted to year 2009 US dollar values). ${ }^{[57]}$ Among those still working, COPD symptoms resulted in an annual loss of \$US880 per participant from lost time at work, and another $10 \%$ reported that their productivity while at work had been limited by respiratory symptoms within the last week.

Very few studies have examined whether COPD treatment can affect indirect costs. An analysis based on one randomized clinical trial of fluticasone propionate in 281 COPD patients found that due to the decreased frequency of exacerbations in the treated group, the indirect cost savings were sufficient to offset the increased cost for treatment. ${ }^{[58]}$ A randomized clinical trial of 74 study subjects who had previously undiagnosed airflow obstruction examined the clinical and economic consequences of an inhaled corticosteroid, fluticasone propionate, versus placebo. ${ }^{[59]}$ The mean age of the treated group was 49.9 years as compared to 44.8 years in the placebo group, and although all were proven to have airflow obstruction by spirometry, most had mild disease. The average number of days that a subject was unable to work or perform their normal daily activities was 3.2 in the treated group and 11.0 in the placebo group, which translated to indirect costs of \$US225 and \$US762, respectively (year 1998 values). The results did not reach statistical significance due to the small study size and high variability in the indirect cost estimates, but the difference more than offset the estimated treatment cost of \$US375 per year. An additional \$US18 per patient per year was saved due to reduced utilization of rescue medications in the treatment group. Because the treated group also had substantial reduction in chronic respiratory symptoms and improved overall health status, the cost per QALY was \$US13016, a favourable estimate compared to other chronic disease therapies.

The recent large clinical trials for salmeterol/ propionate combined (TORCH [TOwards a Revolution in COPD Health] $)^{[60]}$ and for tiotropium bromide (UPLIFT [Understanding Potential Long Term Impact on Function with Tiotropium] $)^{[61]}$ had sufficient patients for sub-analyses that confirmed treatment efficacy among participants with milder COPD or individuals of working age, including reduction in the frequency of exacerbations. Although the information about the impact of newer treatments on indirect costs is still relatively rare, the available data suggest that maintenance and preventive treatments for COPD 
can have substantial indirect cost benefits even in populations where the direct medical costs are only likely to increase.

\section{The Importance of Exacerbations}

The natural history of COPD is that of a condition that slowly progresses over many years, and because few adults regularly push their lung function to maximum capacity, most COPD patients are asymptomatic until they have permanently lost $20 \%$ or more of their lung function. General population studies such as the National Health and Nutrition Examination Survey (NHANES) III have found that more than 50\% of those with significant airflow obstruction are unaware they have a lung disease. ${ }^{[62]}$ Many patients are not diagnosed until they have an acute exacerbation event, which is usually precipitated by acute bronchitis or pneumonia, although many exacerbations have no identifiable aetiology. In our study of 6864 COPD patients from one integrated for-profit healthcare system in the southwestern USA, we found that approximately two-thirds were initially diagnosed during an acute exacerbation, and $18 \%$ were diagnosed during a hospitalization. ${ }^{[63]}$

An exacerbation event is the most common reason for hospitalization of COPD patients, who on average have an annual risk for hospitalization that is two to three times that of age- and gender-matched controls without COPD. ${ }^{[63,64]}$ In a nationwide survey of 602 US hospitals, exacerbations cost an average of \$US647 for an emergency department visit, \$US7242 for a simple 4-day admission, \$US20 757 for a complex admission, and intensive care services were the most costly at \$US44 909 (year 2008 values). ${ }^{[65]}$ In the UK approximately $54 \%$ of the direct medical costs for COPD are attributable to hospitalizations, ${ }^{[66]}$ which is similar to the US estimate of $45 \%{ }^{[1]}$

Exacerbations may be relatively mild and result in only minor increases in respiratory symptoms, or they can be life-threatening by causing respiratory failure or precipitating cardiovascular complications such as acute coronary syndrome or ischaemic stroke. ${ }^{[67]}$ Most exacerbations pass in a few days with only minor and reversible im- pact, but some exacerbations may result in a permanent loss of lung function so that a patient never fully recovers to their pre-hospitalization health status. ${ }^{[68]}$ Because of the great variability in symptoms, severity and complications, the definition of a COPD exacerbation, not surprisingly, is a subject of controversy, with calls for a standardized definition followed by consensus opinions, criticism of these opinions, articles on the merits of various systems, and then more calls for standardized definitions. ${ }^{\text {[68-70] }}$

Fortunately, for the purposes of most pharmacoeconomics research, we are interested primarily in how exacerbations affect healthcare utilization, so one of the earlier and simpler consensus definitions of exacerbations and exacerbation severity works rather well. ${ }^{[71]}$ Mild exacerbations are characterized by an acute and sustained worsening of the patient's respiratory symptoms beyond normal day-to-day variations that result in an increased need for medication, but can be managed in the patient's own normal environment. Moderate exacerbations are those that are severe enough for the patient to seek medical attention in an outpatient setting such as a clinic, urgent care office or emergency centre, plus receive additional medications such as antibacterials or oral corticosteroids. Severe exacerbations are those that result in hospitalization. Certainly this is not a perfect system - it does not account for differences among patients in healthcare-seeking behaviour, limitations in access to healthcare, or variability among providers in diagnosis and treatment. However, it does reflect an important stratification in healthcare costs that is verifiable and useful: mild exacerbations have minimal impact on direct medical costs, moderate exacerbations have modest but measurable direct and indirect medical costs, and severe exacerbations are inevitably expensive. It is also predictable: in our recent analysis that used the natural history of exacerbations within relatively small cohorts to estimate the cost benefit of newer COPD treatments, we found that moderate and severe exacerbations defined by this system could be predicted with very good precision. ${ }^{[39]}$

It was only recently recognized that COPD exacerbations can be prevented. Following the 
introduction of long-acting bronchodilators such as the long-acting $\beta$-agonists (formoterol, salmeterol, indicaterol) and anticholinergic agents (tiotropium bromide), clinicians began to realize that those regularly using these inhaled treatments were having substantially fewer exacerbation events. Inhaled corticosteroids, which are of questionable benefit in terms of their ability to preserve lung function, were nonetheless proven to be of value in reducing the risk for exacerbations. ${ }^{[72]}$ While it has been very difficult to prove that inhaled treatments alter the accelerated decrease in lung function or improve survival in COPD, the realization that regular maintenance therapy with these long-acting inhaled agents could reduce the risk for exacerbations resulted in a rapid evolution in COPD treatment guidelines. Long-acting bronchodilators are now the recommended first-line treatment for all people with moderate or worse COPD. ${ }^{[12]}$ Depending on the treated population and the combination of treatments, the newer therapies of tiotropium bromide and fluticasone propionate/salmeterol have been shown to produce a relative risk reduction for exacerbations ranging from $25 \%$ to $66 \%$. ${ }^{[73]}$

The fact that some COPD treatments reduce exacerbation events, including expensive hospitalizations, raises the possibility that these treatments result in utilization reductions that may partially or completely offset the cost of these new therapies. ${ }^{[7,75]}$ Even a reduction in moderate exacerbations can produce substantial cost offsets, particularly among patients who have two or more exacerbations per year. Therefore, reduction in exacerbations is a useful benefit to target in cost-effectiveness modelling and can be a tangible outcome for calculating incremental costeffectiveness ratios (ICERs). ${ }^{[39,75]}$ Recent analyses by Aaron and colleagues ${ }^{[76]}$ have examined statistical methods for modelling exacerbation events, and have found that threshold regression techniques based on either a Poisson process or a Wiener diffusion process can be used to model the natural history of exacerbation events in a COPD treatment cohort with very good accuracy.

The recent appreciation for the importance of exacerbations in the pathogenesis in clinical outcomes of COPD has led to the description of an 'exacerbation phenotype', or people prone to having two or more exacerbations per year irrespective of their level of baseline lung function impairment. The traditional paradigm of staging COPD by the severity of airflow obstruction is useful and well validated, ${ }^{[77]}$ and has been the foundation of most COPD economic evaluations, but it also has many notable limitations. It is not uncommon to find people with severe airflow obstruction who are relatively asymptomatic, physically active and otherwise healthy, and others with mild to moderate obstruction who are disabled by their pulmonary symptoms and chronic co-morbidities. The ECLIPSE (Evaluation of COPD Longitudinally to Identify Predictive Surrogate Endpoints) study was designed to help reexamine some of the clinical manifestations and endpoints in COPD and identify their biological markers. ${ }^{[78]}$ Using a cohort of 2138 patients, the ECLIPSE study identified a 'frequent exacerbator' phenotype, defined as people who have two or more COPD exacerbations within a year. ${ }^{[79]}$ As expected, frequent exacerbations increase with the severity of airflow obstruction $(22 \%, 33 \%$ and $47 \%$ among Global Initiative for Chronic Obstructive Lung Disease [GOLD] stage 2, 3 and 4, respectively). Because stage 2 COPD patients are far more prevalent than stage 3 or 4 , it is likely that most exacerbations in the general population occur among those with relatively moderate airflow obstruction. In fact, that was observed in one hospital-based study in Spain, where 54\% of patients hospitalized for the first time for an exacerbation of COPD had GOLD stage 1 or 2 at baseline. ${ }^{[80]}$ The ECLIPSE study is one of several ongoing projects that are identifying and validating novel clinical phenotyping and prognostic systems.

As a clinical outcome for examining cost effectiveness, exacerbations may be more interpretable to those with knowledge of COPD than QALYs. Exacerbations are events that both patients and physicians can easily identify and relate to, while QALYs are an abstract construct that may be difficult to assess, and for which underlying utility values have varied greatly. ${ }^{[20,81]}$ However, patients who have experienced exacerbations may be able to quantify what it is worth to them to avoid future 
exacerbations and, in fact, Rutten-van Molken and colleagues ${ }^{[81]}$ are the latest to investigate this potential relationship in their time trade-off valuations.

\section{Cost Utilities in COPD: Quantity of Quality}

While exacerbation events are useful measures of efficacy and outcome in COPD, they are difficult to compare with outcomes of other chronic diseases. Cardiovascular disease also has acute events (acute coronary syndrome, angina attacks, arrhythmias) that make useful clinical endpoints, but it is difficult to say that a COPD exacerbation is equivalent to a 'heart attack', especially when the severity of either is so highly variable. In order to compare the cost effectiveness of COPD treatment to the cost effectiveness of other standard therapies, we need standard units of health impact that are consistent across diseases and disease states. The need for decision makers to have comparability in order to allocate scarce healthcare resources has been previously highlighted, ${ }^{[16,20]}$ and we reiterate the point here.

QALYs are very useful measures for describing treatment value. QALYs, the measurement of utilities multiplied by time periods to create years of varying QOL that are summated over time, describe the amount of optimal quality time that is gained or lost. Utility instruments are developed by asking patients to state their relative preference for a range of health states along a scale from 0 (death or least desirable health) to 1.0 or 100 (perfect or ideal health). The negative impact of an event such as a COPD exacerbation on overall health, or the positive impact of a new treatment that prevents this decrease or improves health, can then be quantified on this scale. The cost effectiveness of a new COPD treatment can thus be described as the cost of the new treatment per QALY, which can then be compared to the cost-per-QALY of a cardiovascular treatment, cancer treatment or any other disease where that instrument has been validated. There are two methods for calculating QALY utility scores: direct preference measurement (e.g. standard gam- ble, time trade-off) and using a health-related QOL (HR-QOL) survey. The former method is time and resource intensive, optimally using face-to-face interviews. Consequently, the latter method of using HR-QOL surveys is more commonly used.

There are currently two well validated QALY instruments for COPD: the Quality of Well Being Scale (QWB) and the EQ-5D. The QWB was developed by Kaplan and others ${ }^{[82]}$ at the University of California - San Diego (San Diego, CA, USA) in the 1970s as a general health status instrument, but COPD was one of the first chronic diseases examined to prove that the QWB was also sensitive to changes in health status within one chronic disease area. Since then it has been validated in large clinical studies including the NETT (the National Emphysema Treatment Trial). ${ }^{[83,84]}$ The QWB has also been demonstrated to have excellent sensitivity to changes that are the result of COPD interventions, ${ }^{[85,86]}$ have good correlation with COPD-specific QOL instruments ${ }^{[86]}$ and be a predictor of survival. ${ }^{[87]}$ The QWB was also used to estimate the cost per QALY in NETT. ${ }^{[88]}$ Unfortunately, the QWB has rarely been used to calculate the cost per QALY otherwise, and the limited number of studies that have directly compared the QWB with other general health status instruments have found substantial variability among them. ${ }^{[89]}$ The QWB also has the disadvantage of being a much longer questionnaire: it requires about 11 minutes to administer the QWB by phone, as compared with about 2 minutes for the EQ-5D. ${ }^{[90]}$

The EQ-5D is a simple instrument that assesses basic limitations (no problems, some problems or extreme problems) in five dimensions (mobility, self-care, usual activity, pain/discomfort and anxiety/depression). Although it was developed in Europe, US preference weights have been calculated in a nationwide survey of more than 4000 adults. ${ }^{[91]}$ Largely because of the shorter administration time and the increased emphasis in Europe on demonstrating the cost effectiveness of new treatments, the overall number of published studies using the EQ-5D is far greater than for the QWB, including those that are specific to COPD.$^{[57]}$ The performance characteristics of the 
EQ-5D were described and validated in COPD in large studies from several countries. ${ }^{\left[{ }^{[2-96]}\right.}$ The EQ-5D has shown good responsiveness to moderate COPD exacerbations, ${ }^{[97]}$ and in one large epidemiological study in Spain, the EQ-5D was able to detect the health impact of a relatively minor and controversial defect in airflow obstruction. ${ }^{[98]}$ However, the ceiling effect is a known limitation of the EQ-5D, ${ }^{[99]}$ and in a study of the effects of a pulmonary rehabilitation programme the ceiling effect appeared to limit the responsiveness. ${ }^{[100]}$ Nevertheless, the EQ-5D has increasingly been employed to calculate the cost per QALY of newer COPD treatments. ${ }^{[35,41,42,101-104]}$ Because psychometric instruments tend to gain credibility with use, and because the National Institute for Health and Clinical Excellence tends to accept the EQ-5D as a valid tool for assessing QALYs, the EQ-5D will most likely continue to grow in its dominance as the preferred instrument for describing overall health status and QALYs in COPD.

A concern about these standard QALY instruments is that they may underestimate the impact that short but severe exacerbation events may have on long-term QALYs. To address this problem, Rutten-van Molken and colleagues ${ }^{[81]}$ developed 16 distinct COPD health profiles and then surveyed 239 patients to value them using visual analogue scales and time trade-off methods. Their intriguing work confirms that COPD patients have reduced utility scores for periods long after most airflow has returned to normal, and that health profiles are a useful way to more accurately capture the varied health states associated with COPD exacerbations. ${ }^{[81]}$

\section{The Importance of Co-Morbidities}

Approximately $80 \%$ of COPD cases worldwide are attributable to cigarette smoking, and the proportion is probably higher in countries where woodstoves and biomass are not used for cooking and indoor heating. Cigarette smoking and inhalation of other carbon-based particulates cause a wide variety of health effects beyond COPD, leading to co-existing morbidities that can have a confounding or additive effect on COPD utiliza- tion. Case-control analyses show that COPD patients have increased utilization in almost every disease category, but most especially in those categories directly attributable to cigarette smoking such as lung cancer and cardiovascular disease. ${ }^{[64,105,106]}$ Additionally, some diseases that are not as commonly associated with cigarette smoking, such as gastric ulcers and dyspepsia, are nonetheless substantially increased in COPD. ${ }^{64,105,107]}$

Large prospective clinical trials and cohort studies help demonstrate the impact of comorbidities in COPD. The LHS (Lung Health Study) was a randomized clinical trial of smoking cessation and inhaled ipratropium therapy in 5887 smokers with mild to moderate COPD. Over 14.5 years of follow-up, lung cancer was the most common cause of death among LHS participants $(n=240$ [33\% of all deaths]), followed by cardiovascular diseases $(n=163$ [22\%]) and cancer of organs other than the lungs $(n=154[21 \%])$, with respiratory non-cancer deaths relatively uncommon $(n=57[8 \%]) \cdot{ }^{[108]}$ In the TORCH study, the probability of having a cardiovascular adverse event over the 3 years of follow-up ranged from $20.8 \%$ to $24.3 \%$, which was not significantly different among the four treatment arms but higher than the probability of having pneumonia (12.3$19.6 \%)^{[109,110]}$ In an analysis of 1986 people who had lung function testing as part of the populationbased OLIN survey in Sweden, those with mild COPD had a substantially increased prevalence of diagnosed cardiovascular disease $(48 \%)$ as compared with similar people with normal lung function $(41 \%)$, and increased to $53 \%$ for those with stage II COPD. ${ }^{[107]}$ Smoking cessation is undoubtedly the most cost-effective intervention among those COPD patients who are still smoking, largely due to the reduction in co-morbidities. Even in the LHS where only $11 \%$ of patients were able to achieve complete abstinence from cigarettes at 12 months, those who were able to quit have significantly improved all-cause survival, mostly due to the reduction in cardiovascular diseases. ${ }^{[108]}$

Safety data from randomized clinical trials suggest that newer COPD treatments can reduce the risk of some co-morbidities, including major cardiovascular events, although the available data 
are limited because individuals with multiple chronic conditions are under-represented in randomized clinical trials. ${ }^{[111]}$ In a pooled analysis of clinical trials, users of tiotropium bromide had a $17 \%$ reduction in major cardiovascular events, and $23 \%$ reduction in fatal cardiovascular events, versus placebo $\left(\mathrm{p}<0.05\right.$ for both). ${ }^{[12]}$ Cardiovascular events were reduced by $14 \%$ among users of salmeterol/fluticasone combined versus placebo in the 3-year TORCH study. ${ }^{[10]}$ In clinical trials for indacaterol, a long-acting once-a-day inhaled $\beta$-agonist, treatment was associated with consistently lower cardiovascular events, although the hazard ratio reductions did not reach statistical significance in these short-term studies where the event rates tend to be low. ${ }^{[13,114]}$ Co-morbidityassociated event data are very limited even in clinical trials because they are usually captured as adverse events and not primary or secondary endpoints. Studies that have compared the cause of death in the opinions of adjudication panels with the opinions of local investigators have found wide discrepancies. ${ }^{[15,116]}$ Nevertheless, the available data suggest that therapies that reduce COPD exacerbation events also cause beneficial reductions in the risk for major cardiovascular events.

Estimating the cost benefits of a reduction in co-morbidity-related events is a challenge, but ignoring the impact of co-morbidities is likely to result in a substantial underestimate of treatment cost benefits. There are relatively few COPD cost analyses that have included detailed information on co-morbidities. ${ }^{[63,64,117-120]}$ In a multifactorial analysis of direct medical costs, we found that the presence of co-morbidities was a stronger predictive factor for high future costs than the degree of airflow obstruction. ${ }^{[19]}$ COPD and cardiovascular disease utilization are heavily confounded due to the high prevalence of cardiovascular disease among COPD patients, the increased morbidity of exacerbations among those with both cardiovascular disease and COPD,${ }^{[121]}$ and the increased risk for subsequent cardiovascular events among those with COPD exacerbations. ${ }^{[67]}$

One approach to dealing with co-morbidities is to simply attribute all utilization occurring during an exacerbation to COPD, then attribute all care occurring during other time intervals to 'usual care'. ${ }^{[39]}$ This strategy assumes that the comorbidity-related utilization that occurs during an exacerbation would have been avoided had the exacerbation also been avoided. Although this strategy is logical and straightforward, an important limitation is that one has to make an assumption about the average duration of an exacerbation, and there is limited information on how best to estimate this. One of the few cohort studies that have prospectively examined this issue found that the average exacerbation that does not result in hospitalization is resolved within a week, but approximately $25 \%$ had detectable effects after 35 days, and $7 \%$ had still not recovered their previous lung function at 90 days ${ }^{[68]}$ Longitudinal studies that have examined total healthcare costs before and after the initial diagnosis, which is commonly associated with exacerbation events, show that utilization attains a new baseline after 60 days, suggesting that 60 days should be the maximum exacerbation interval. ${ }^{[63,122]}$

\section{Markov Modelling: Tried but True?}

Traditionally, COPD has been described as a slowly progressive disease with its severity divided into four stages ranging from one (mild obstruction with reduction in the $\mathrm{FEV}_{1} /$ forced vital capacity ratio but $\mathrm{FEV}_{1}$ greater than $80 \%$ of predicted value, and likely to be minimally symptomatic) to 4 (severe obstruction with $\mathrm{FEV}_{1}$ less than $30 \%$ of predicted value, and likely to be dependent on supplemental oxygen). ${ }^{[77]}$ In early concepts of COPD progression, the accelerated decline in airflow was described as a steady linear function, ${ }^{[123]}$ and when patients managed to quit smoking the rate of decline would revert to the same normal rate of airflow decline experienced by never-smokers. This traditional COPD concept of progression is well suited to modelling using basic Markov modelling techniques and has been widely used in COPD treatment cost-effectiveness analyses to model transitions across stages. All but four of the modelling studies published in 2004 or later that we reviewed used Markov processes (see SDC).

The concepts of pathogenesis and progression of COPD on which these traditional models are based are being called into question. ${ }^{[124]} \mathrm{Re}$ - 
cent cohort studies have demonstrated that while the mean group changes over time support the Fletcher-Peto concept of progressive losses in airflow over time, the changes in lung function and disease states among individual COPD patients are highly variable. ${ }^{[125]}$ COPD exacerbations and other serious events can result in permanent lung injury and change in health status, and for affected individuals their airflow decline is more likely to resemble a step function with sudden declines associated with acute events against a background of relatively slow and steady decline. ${ }^{[126,127]}$ Furthermore, some patients continue to have an accelerated rate of decline even after they stop smoking, ${ }^{[128]}$ which may represent inflammatory mechanisms that continue to be deranged long after the noxious exposure is gone. The impact of exacerbations on lung function appears to be heterogeneous across populations and not always apparent depending on the population and study design. ${ }^{[129]}$ In the most recent version of the GOLD statement, the concept of COPD staging has been discarded altogether. ${ }^{[12]}$ The degree of airflow obstruction is still described in four 'grades', but it is specifically acknowledged that a staging system based on $\mathrm{FEV}_{1}$ alone is inadequate and that evidence for an alternative staging system does not exist. ${ }^{[12]}$ Increasingly, COPD is being understood as a disease with a high degree of variability in exacerbation experience and disease progression, and the basis for describing disease state transitions in COPD used in these Markov models bears reconsideration.

As we have already noted, it was recently established that a substantial proportion of COPD patients have an exacerbation phenotype, and the fundamental characteristic of this phenotype is that the frequency of exacerbation events does predict future outcomes. ${ }^{[79]}$ While it is theoretically possible to use advanced techniques such as tunnel states to allow integration of COPD exacerbations and other events from prior cycles to modify individual probabilities, these still introduce unstable assumptions about the risk for exacerbations, their severity and duration, and impact on co-morbid conditions.

Using the Markov modelling approach is a very well established and flexible technique and software for creating Markov models is widely available. However, there needs to be a careful reconsideration of what most accurately describes a disease state transition in COPD and how to best model the great heterogeneity in disease progression. The percentage of predicted $\mathrm{FEV}_{1}$ will always be a useful diagnostic measure for COPD, but it is a weak correlate of most clinically relevant outcomes, including survival. ${ }^{[130]}$ Multidimensional staging tools such as the BODE Index (which takes into account Body mass index, airway $\mathrm{Ob}-$ struction, Dyspnoea and Exercise tolerance) have been proven to be better predictors of clinical outcomes, but until current longitudinal studies with these measures are completed, there is very little long-term epidemiological information on the natural history of COPD on which to base comprehensive Markov models.

Recent papers have explored the appropriateness of decision-tree, Markov, and discrete-event or micro-simulation models for health-related economic models. ${ }^{[131-133]}$ Each type of model has its advantages and disadvantages. More complex models require more detailed information and advanced modelling skills and often lack transparency for decision makers, but they may provide more realistic assessments of complex diseases. Unfortunately, there are not many published examples of good alternatives to Markov models for COPD treatments, but in health economic evaluations of smoking cessation treatments, a patient-level simulation model (a.k.a. Monte Carlo micro-simulation model) has been successfully applied to model outcomes over extended horizons and validated using international epidemiological data. ${ }^{[134]}$ It is reasonable to expect that models for smoking cessation are likely to also work well for modelling COPD treatments, since smoking cessation is in itself a COPD treatment, and it shares the problem of having multiple potential interventions, a wide range of outcomes and co-morbidities, and variable treatment compliance states. One compelling advantage microsimulation models have over Markov models is the ability to model multiple events during a time interval (e.g. a COPD exacerbation and a heart attack) as well as incorporating an individual's history of events into their probability estimates. ${ }^{[132]}$ 


\section{The Problem of Outliers}

As we have already noted, COPD patients have a high risk for hospitalization due to exacerbation and other causes. Because these events may precipitate respiratory failure, admission to an intensive care unit and prolonged mechanical ventilation, it is not unusual for a number of COPD patients to have total direct medical costs that are more than ten times greater than average. In a survey of COPD hospitalizations in 602 hospitals from across the US, complicated admissions accounted for only $5.8 \%$ of the care, but $20.9 \%$ of the total costs, and mean costs for intensive care unit admissions were \$US44 909 as compared with \$US7242 for simple hospital admissions (year 2008 values). ${ }^{[65]}$

COPD is an example of a condition where the distribution of the annual total direct medical cost across a population will range from a substantial proportion with zero cost to a handful with cost of a half a million dollars or more. The presence in econometric modelling of cost data with a 'heavy' upper tail has previously been raised as an important issue. ${ }^{[135]}$ Transformation of cost data using a log scale is one common method of shortening a long right tail and decreasing the influence of outliers, but is not useful in cost-effectiveness studies in which an ICER is assessed. Frequently, the mean may be much greater than the median value for most patients; however, use of a distribution statistic other than the mean in calculating an ICER is not recommended. ${ }^{[136]}$ Large sample sizes are robust to tail problems, but in a relatively small study population the effects of even one outlier may be very dramatic. In a cost analysis of a clinical trial of controller therapy in 449 COPD patients in Canada, inclusion of one individual who had a prolonged hospitalization changed the ICER estimate for cost per exacerbation avoided from \$US3876 to \$US6510 (year 2004 values). ${ }^{[137]}$ Clearly, newer treatments can reduce the risk for exacerbations, and there is some evidence suggesting that the severity of exacerbations amongst those still having them is decreased ${ }^{[138]}$ However, it is not known whether these catastrophic events that result in extremely high cost for a few individuals can be avoided.
Occasionally, outliers are related to data entry or processing errors, and researchers using published cost estimates rely on analysts in clinical trials or observational studies to perform comprehensive reviews of data values and include explanation of outliers in reports, but due to space limitations, manuscripts cannot include all study details, and potential causes of cost outliers are rarely discussed. Until extreme outliers are better understood, it is reasonable and advisable to decide how outliers will be dealt with a priori as part of the study analysis plan. For most current models this entails performing sensitivity analyses on cost assumptions.

\section{Conclusions}

Fortunately, the recent development of several new treatments for COPD has changed the overall management philosophy from a sense of nihilism and palliative symptom management to a more optimistic outlook and proactive therapy. ${ }^{[139]}$ The availability of new treatments has also prompted an explosion of new clinical research in this disease plus the recognition that some of our old paradigms have serious flaws that could not explain many common clinical findings. As new paradigms are developed to explain the spectrum of clinical presentations, pathophysiology and natural history of this disease, the approaches to cost-effectiveness analysis will also need to adapt. This is a welcome problem for the millions of patients who are affected by this disease and those who are interested in helping them.

Among patients with diagnosed COPD, the greatest proportion of direct medical costs have been for hospital care, most of which is directly attributable to COPD exacerbations and co-morbid complications. Fortunately, several of the newer COPD treatments are proven to reduce the risk for exacerbations that lead to hospitalization, and thus are likely to be cost effective. However, even among patients with milder symptomatic disease, the impact of COPD on lost days at work and other indirect costs make it likely that treatment is cost effective from the societal perspective even among those who are not being hospitalized. Direct comparison of the cost utility of COPD treatment with 
other chronic disease therapies is likely to demonstrate that the newer COPD treatments are among the most cost-effective chronic disease treatments available, and thus might convince the clinical nihilists (unfortunately, who are still not uncommon) that COPD treatment is worth everyone's effort.

\section{Acknowledgements}

No financial support was received for this study. The authors have declared no conflicts of interest that are directly relevant to the content of this review.

Dr Mapel was the lead author and created the overall design and the initial draft. Dr Roberts contributed to the drafting and revision of all sections and created the tables for the literature review that appear in the SDC. Dr Mapel is the guarantor of the overall content.

\section{References}

1. National Heart, Lung, and Blood Institute. Morbidity \& mortality: 2009 chart book on cardiovascular, lung, and blood diseases [online]. Available from URL: http://www. nhlbi.nih.gov/resources/docs/2009_ChartBook.pdf [Accessed 2012 Jan 5]

2. Van Wave TW, Scutchfield FD, Honore PA. Recent advances in public health systems research in the United States. Annual review of public health, vol. 31. Palo Alto (CA): Annual Reviews, 2010: 283-95

3. CDC. Deaths from chronic obstructive pulmonary disease: United States, 2000-2005. MMWR Morb Mortal Wkly Rep 2008 Nov 14; 57 (45): 1229-32

4. Mannino DM, Homa DM, Ford ES, et al. Chronic obstructive pulmonary disease surveillance: United States, 1971-2000. MMWR Surveill Summ 2002 Aug 2; 51 (6): 1-16

5. Trupin L, Earnest G, San Pedro M, et al. The occupational burden of chronic obstructive pulmonary disease. Eur Respir J 2003 Sep; 22 (3): 462-9

6. Eisner MD, Yelin EH, Trupin L, et al. The influence of chronic respiratory conditions on health status and work disability. Am J Public Health 2002 Sep; 92 (9): 1506-13

7. Stewart AL, Greenfield S, Hays RD, et al. Functional status and well-being of patients with chronic conditions: results from the Medical Outcomes Study. JAMA 1989 Aug 18; 262 (7): 907-13

8. Blanc PD, Menezes AM, Plana E, et al. Occupational exposures and COPD: an ecological analysis of international data. Eur Respir J 2009 Feb; 33 (2): 298-304

9. Wouters EF. Economic analysis of the Confronting COPD survey: an overview of results. Respir Med 2003 Mar; 97 Suppl. C: S3-14

10. Machlin S, Chowdhury S. Expenses and characteristics of physician visits in different ambulatory care settings, 2008. MEPS Statistical Brief \#318, March 2011 [online]. Available from URL: http://www.meps.ahrq.gov/mepsweb/data files/ publications/st318/stat318.pdf [Accessed 2012 Jan 5]

11. Soni A. Top 10 most costly conditions among men and women, 2008: estimates for the U.S. civilian non- institutionalized adult population, age 18 and older. MEPS Statistical Brief \#331, July 2011 [online]. Available from URL: http://www.meps.ahrq.gov/mepsweb/data files/publications/st331/stat331.shtml [Accessed $201 \overline{2}$ Jan 5]

12. Global Initiative for Chronic Obstructive Lung Disease (GOLD). Global strategy for the diagnosis, management and prevention of COPD, 2011 [online]. Available from URL: http://www.goldcopd.org/guidelines-global-strategyfor-diagnosis-management.html [Accessed 2012 Jan 5]

13. Molken MP, Van Doorslaer EK, Rutten FF. Economic appraisal of asthma and COPD care: a literature review 1980-1991. Soc Sci Med 1992 Jul; 35 (2): 161-75

14. Ruchlin HS, Dasbach EJ. An economic overview of chronic obstructive pulmonary disease. Pharmacoeconomics 2001; 19 (6): 623-42

15. Ramsey SD. Suboptimal medical therapy in COPD: exploring the causes and consequences. Chest $2000 \mathrm{Feb}$; 117 (2 Suppl.): 33S-7S

16. Ramsey SD, Sullivan SD. The burden of illness and economic evaluation for COPD. Eur Respir J Suppl 2003 Jun; 41: 29s-35s

17. D’Souza AO, Smith MJ, Miller LA, et al. An appraisal of pharmacoeconomic evidence of maintenance therapy for COPD. Chest 2006 Jun; 129 (6): 1693-708

18. Critical assessment of economic evaluation. In: Drummond M, O'Brien BJ, Stoddart GL, et al. Methods for the economic evaluation of health care programmes. New York: Oxford University Press, 1997: 27-51

19. Rutten-van Molken M, Lee TA. Economic modeling in chronic obstructive pulmonary disease. Proc Am Thorac Soc 2006 Sep; 3 (7): 630-4

20. Starkie HJ, Briggs AH, Chambers MG. Pharmacoeconomics in COPD: lessons for the future. Int J Chron Obstruct Pulmon Dis 2008; 3 (1): 71-88

21. Ferdinands JM, Mannino DM. Obstructive lung disease models: what is valid? COPD 2008 Dec; 5 (6): 382-93

22. Borg S, Ericsson A, Wedzicha J, et al. A computer simulation model of the natural history and economic impact of chronic obstructive pulmonary disease. Value Health 2004 Mar-Apr; 7 (2): 153-67

23. Hoogendoorn M, Rutten-van Molken MP, Hoogenveen $\mathrm{RT}$, et al. A dynamic population model of disease progression in COPD. Eur Respir J 2005 Aug; 26 (2): 223-33

24. Oostenbrink JB, Rutten-van Molken MP, Monz BU, et al. Probabilistic Markov model to assess the cost-effectiveness of bronchodilator therapy in COPD patients in different countries. Value Health 2005 Jan-Feb; 8 (1): 32-46

25. Sin DD, Golmohammadi K, Jacobs P. Cost-effectiveness of inhaled corticosteroids for chronic obstructive pulmonary disease according to disease severity. Am J Med 2004 Mar 1; 116 (5): 325-31

26. Spencer M, Briggs AH, Grossman RF, et al. Development of an economic model to assess the cost effectiveness of treatment interventions for chronic obstructive pulmonary disease. Pharmacoeconomics 2005; 23 (6): 619-37

27. Ramsey S, Willke R, Briggs A, et al. Good research practices for cost-effectiveness analysis alongside clinical trials: the ISPOR RCT-CEA Task Force report. Value Health 2005 Sep-Oct; 8 (5): 521-33 
28. McGhan WF, Al M, Doshi JA, et al. The ISPOR Good Practices for Quality Improvement of Cost-Effectiveness Research Task Force Report. Value Health 2009 Nov-Dec; 12 (8): 1086-99

29. van der Palen J, Monninkhof E, van der Valk P, et al. Cost effectiveness of inhaled steroid withdrawal in outpatients with chronic obstructive pulmonary disease. Thorax 2006 Jan; 61 (1): 29-33

30. Lee KH, Phua J, Lim TK. Evaluating the pharmacoeconomic effect of adding tiotropium bromide to the management of chronic obstructive pulmonary disease patients in Singapore. Respir Med 2006 Dec; 100 (12): 2190-6

31. Dal NR, Eandi M, Pradelli L, et al. Cost-effectiveness and healthcare budget impact in Italy of inhaled corticosteroids and bronchodilators for severe and very severe COPD patients. Int J Chron Obstruct Pulmon Dis 2007; 2 (2): 169-76

32. Rutten-van Molken MP, Oostenbrink JB, Miravitlles M, et al. Modelling the 5-year cost effectiveness of tiotropium, salmeterol and ipratropium for the treatment of chronic obstructive pulmonary disease in Spain. Eur J Health Econ 2007 Jun; 8 (2): 123-35

33. Bartolomeo N, Trerotoli P, Moretti A, et al. A Markov model to evaluate hospital readmission. BMC Med Res Methodol 2008; 8: 23

34. Chuck A, Jacobs P, Mayers I, et al. Cost-effectiveness of combination therapy for chronic obstructive pulmonary disease. Can Respir J 2008 Nov-Dec; 15 (8): 437-43

35. Earnshaw SR, Wilson MR, Dalal AA, et al. Costeffectiveness of fluticasone propionate/salmeterol (500/50 microg) in the treatment of COPD. Respir Med 2009 Jan; 103 (1): 12-21

36. Nielsen R, Johannessen A, Benediktsdottir B, et al. Present and future costs of COPD in Iceland and Norway: results from the BOLD study. Eur Respir J 2009 Oct; 34 (4): 850-7

37. Oba Y. Cost-effectiveness of salmeterol, fluticasone, and combination therapy for COPD. Am J Manag Care 2009 Apr; 15 (4): 226-32

38. Gani R, Griffin J, Kelly S, et al. Economic analyses comparing tiotropium with ipratropium or salmeterol in UK patients with COPD. Prim Care Respir J 2010 Mar; 19 (1): 68-74

39. Mapel DW, Schum M, Lydick E, et al. A new method for examining the cost savings of reducing COPD exacerbations. Pharmacoeconomics 2010; 28 (9): 733-49

40. Neyt M, Devriese S, Thiry N, et al. Tiotropium's costeffectiveness for the treatment of COPD: a cost-utility analysis under real-world conditions. BMC Pulm Med 2010; 10: 47

41. Hoogendoorn M, Rutten-van Molken MP, Hoogenveen RT, et al. Developing and applying a stochastic dynamic population model for chronic obstructive pulmonary disease. Value Health 2011 Dec; 14 (8): 1039-47

42. Price D, Gray A, Gale R, et al. Cost-utility analysis of indacaterol in Germany: a once-daily maintenance bronchodilator for patients with COPD. Respir Med 2011 Nov; 105 (11): 1635-47

43. Zaniolo O, Iannazzo S, Pradelli L, et al. Pharmacoeconomic evaluation of tiotropium bromide in the long-term treatment of chronic obstructive pulmonary disease (COPD) in Italy. Eur J Health Econ 2012 Feb; 13 (1): 71-80
44. Foster TS, Miller JD, Marton JP, et al. Assessment of the economic burden of COPD in the U.S.: a review and synthesis of the literature. COPD 2006 Dec; 3 (4): 211-8

45. Centers for Disease Control and Prevention (CDC). Prevalence and most common causes of disability among adults: United States, 2005. MMWR Morb Mortal Wkly Rep 2009 May 1; 58 (16): 421-6

46. Centers for Disease Control and Prevention (CDC). Smoking-attributable mortality, years of potential life lost, and productivity losses: United States, 2000-2004. MMWR Morb Mortal Wkly Rep 2008 Nov 14; 57 (45): 1226-8

47. Tinkelman D, Nordyke RJ, Isonaka S, et al. The impact of chronic obstructive pulmonary disease on long-term disability costs. J Manag Care Pharm 2005 Jan-Feb; 11 (1): 25-32

48. Halpern MT, Stanford RH, Borker R. The burden of COPD in the U.S.A.: results from the Confronting COPD survey. Respir Med 2003 Mar; 97 Suppl. C: S81-9

49. Chapman KR, Bourbeau J, Rance L. The burden of COPD in Canada: results from the Confronting COPD survey. Respir Med 2003 Mar; 97 Suppl. C: S23-31

50. Britton M. The burden of COPD in the U.K.: results from the Confronting COPD survey. Respir Med 2003 Mar; 97 Suppl. C: S71-9

51. Izquierdo JL. The burden of COPD in Spain: results from the Confronting COPD survey. Respir Med 2003 Mar; 97 Suppl. C: S61-9

52. Wouters EF. The burden of COPD in the Netherlands: results from the Confronting COPD survey. Respir Med 2003 Mar; 97 Suppl. C: S51-9

53. Dal Negro R, Rossi A, Cerveri I. The burden of COPD in Italy: results from the Confronting COPD survey. Respir Med 2003 Mar; 97 Suppl. C: S43-50

54. Piperno D, Huchon G, Pribil C, et al. The burden of COPD in France: results from the Confronting COPD survey. Respir Med 2003 Mar; 97 Suppl. C: S33-42

55. Jansson SA, Andersson F, Borg S, et al. Costs of COPD in Sweden according to disease severity. Chest 2002 Dec; 122 (6): 1994-2002

56. Dal Negro RW, Tognella S, Tosatto R, et al. Costs of chronic obstructive pulmonary disease (COPD) in Italy: the SIRIO study (Social Impact of Respiratory Integrated Outcomes). Respir Med 2008 Jan; 102 (1): 92-101

57. Fletcher MJ, Upton J, Taylor-Fishwick J, et al. COPD uncovered: an international survey on the impact of chronic obstructive pulmonary disease [COPD] on a working age population. BMC Public Health 2011; 11: 612

58. Ayres JG, Price MJ, Efthimiou J. Cost-effectiveness of fluticasone propionate in the treatment of chronic obstructive pulmonary disease: a double-blind randomized, placebo-controlled trial. Respir Med 2003 Mar; 97 (3): 212-20

59. van den Boom G, Rutten-van Molken MP, Molema J, et al. The cost effectiveness of early treatment with fluticasone propionate 250 microg twice a day in subjects with obstructive airway disease: results of the DIMCA program. Am J Respir Crit Care Med 2001 Dec 1; 164 (11): 2057-66

60. Jenkins CR, Jones PW, Calverley PM, et al. Efficacy of salmeterol/fluticasone propionate by GOLD stage of 
chronic obstructive pulmonary disease: analysis from the randomised, placebo-controlled TORCH study. Respir Res 2009; 10: 59

61. Morice AH, Celli B, Kesten S, et al. COPD in young patients: a pre-specified analysis of the four-year trial of tiotropium (UPLIFT). Respir Med 2010 Nov; 104 (11): 1659-67

62. Mannino DM, Gagnon RC, Petty TL, et al. Obstructive lung disease and low lung function in adults in the United States: data from the National Health and Nutrition Examination Survey, 1988-1994. Arch Intern Med 2000 Jun 12; 160 (11): 1683-9

63. Mapel DW, Robinson SB, Dastani HB, et al. The direct medical costs of undiagnosed chronic obstructive pulmonary disease. Value Health 2008 Jul-Aug; 11 (4): 628-36

64. Mapel DW, Hurley JS, Frost FJ, et al. Health care utilization in chronic obstructive pulmonary disease: a casecontrol study in a health maintenance organization. Arch Intern Med 2000 Sep 25; 160 (17): 2653-8

65. Dalal AA, Shah M, D'Souza AO, et al. Costs of COPD exacerbations in the emergency department and inpatient setting. Respir Med 2011 Mar; 105 (3): 454-60

66. Halpin DM. Health economics of chronic obstructive pulmonary disease. Proc Am Thorac Soc 2006 May; 3 (3): 227-33

67. Donaldson GC, Hurst JR, Smith CJ, et al. Increased risk of myocardial infarction and stroke following exacerbation of COPD. Chest 2010 May; 137 (5): 1091-7

68. Seemungal TA, Donaldson GC, Bhowmik A, et al. Time course and recovery of exacerbations in patients with chronic obstructive pulmonary disease. Am J Respir Crit Care Med 2000 May; 161 (5): 1608-13

69. Burge S, Wedzicha JA. COPD exacerbations: definitions and classifications. Eur Resp J Suppl 2003 Jun; 41: 46s-53s

70. Effing TW, Kerstjens HA, Monninkhof EM, et al. Definitions of exacerbations: does it really matter in clinical trials on COPD? Chest 2009 Sep; 136 (3): 918-23

71. Rodriguez-Roisin R. Toward a consensus definition for COPD exacerbations. Chest 2000 May; 117 (5 Suppl. 2): 398S-401S

72. Baker WL, Baker EL, Coleman CI. Pharmacologic treatments for chronic obstructive pulmonary disease: a mixedtreatment comparison meta-analysis. Pharmacotherapy 2009 Aug; 29 (8): 891-905

73. Mapel DW, Hurley JS, Dalal AA, et al. The role of combination inhaled corticosteroid/long-acting beta-agonist therapy in COPD management. Prim Care Respir J 2010 Jun; 19 (2): 93-103

74. Naik S, Kamal KM, Keys PA, et al. Evaluating the costeffectiveness of tiotropium versus salmeterol in the treatment of chronic obstructive pulmonary disease. Clinicoecon Outcomes Res 2010; 2: 25-36

75. Mittmann N, Hernandez P, Mellstrom C, et al. Cost effectiveness of budesonide/formoterol added to tiotropium bromide versus placebo added to tiotropium bromide in patients with chronic obstructive pulmonary disease: Australian, Canadian and Swedish healthcare perspectives. Pharmacoeconomics 2011 May; 29 (5): 403-14

76. Aaron SD, Ramsay T, Vandemheen K, et al. A threshold regression model for recurrent exacerbations in chronic obstructive pulmonary disease. J Clin Epidemiol 2010 Dec; 63 (12): 1324-31

77. Workshop report: 2005 update. Global strategy for diagnosis, management, and prevention of chronic obstructive pulmonary disease [online]. Available from URL: http:// goldcopd.org/guidelines-global-strategy-for-diagnosis-man agement.html [Accessed 2012 Jan 5]

78. Vestbo J, Anderson W, Coxson HO, et al. Evaluation of COPD Longitudinally to Identify Predictive Surrogate End-points (ECLIPSE). Eur Respir J 2008 Apr; 31 (4): 869-73

79. Hurst JR, Vestbo J, Anzueto A, et al. Susceptibility to exacerbation in chronic obstructive pulmonary disease. N Engl J Med 2010 Sep; 363 (12): 1128-38

80. Balcells E, Anto JM, Gea J, et al. Characteristics of patients admitted for the first time for COPD exacerbation. Respir Med 2009 Sep; 103 (9): 1293-302

81. Rutten-van Molken MP, Hoogendoorn M, Lamers LM. Holistic preferences for 1-year health profiles describing fluctuations in health: the case of chronic obstructive pulmonary disease. Pharmacoeconomics 2009; 27 (6): 465-77

82. Kaplan RM, Atkins CJ, Timms R. Validity of a quality of well-being scale as an outcome measure in chronic obstructive pulmonary disease. J Chronic Dis 1984; 37 (2): 85-95

83. Benzo RP, Chang CC, Farrell MH, et al. Physical activity, health status and risk of hospitalization in patients with severe chronic obstructive pulmonary disease. Respiration 2010; 80 (1): 10-8

84. Moy ML, Reilly JJ, Ries AL, et al. Multivariate models of determinants of health-related quality of life in severe chronic obstructive pulmonary disease. J Rehabil Res Dev 2009; 46 (5): 643-54

85. Kaplan RM. The minimally clinically important difference in generic utility-based measures. COPD 2005 Mar; 2 (1): 91-7

86. Kaplan RM, Ries AL, Reilly J, et al. Measurement of health-related quality of life in the National Emphysema Treatment Trial. Chest 2004 Sep; 126 (3): 781-9

87. Martinez FJ, Foster G, Curtis JL, et al. Predictors of mortality in patients with emphysema and severe airflow obstruction. Am J Respir Crit Care Med 2006 Jun 15; 173 (12): 1326-34

88. Ramsey SD, Berry K, Etzioni R, et al. Cost effectiveness of lung-volume-reduction surgery for patients with severe emphysema. N Engl J Med 2003 May 22; 348 (21): 2092-102

89. Hays RD, Kim S, Spritzer KL, et al. Effects of mode and order of administration on generic health-related quality of life scores. Value Health 2009 Sep; 12 (6): 1035-9

90. Fryback DG, Dunham NC, Palta M, et al. US norms for six generic health-related quality-of-life indexes from the National Health Measurement study. Med Care 2007 Dec; 45 (12): 1162-70

91. Shaw JW, Johnson JA, Coons SJ. US valuation of the EQ-5D health states: development and testing of the D1 valuation model. Med Care 2005 Mar; 43 (3): 203-20

92. Naberan K, Azpeitia A, Cantoni J, et al. Impairment of quality of life in women with chronic obstructive pulmonary disease. Respir Med 2012; 106 (3): 367-73 
93. Miravitlles M, Naberan K, Cantoni J, et al. Socioeconomic status and health-related quality of life of patients with chronic obstructive pulmonary disease. Respiration 2011; 82 (5): 402-8

94. Miravitlles M, Llor C, de Castellar R, et al. Validation of the COPD severity score for use in primary care: the NEREA study. Eur Respir J 2009 Mar; 33 (3): 519-27

95. Rutten-van Molken MP, Oostenbrink JB, Tashkin DP et al. Does quality of life of COPD patients as measured by the generic EuroQol five-dimension questionnaire differentiate between COPD severity stages? Chest 2006 Oct; 130 (4): 1117-28

96. Stahl E, Jansson SA, Jonsson AC, et al. Health-related quality of life, utility, and productivity outcomes instruments: ease of completion by subjects with COPD. Health Qual Life Outcomes 2003; 1: 18

97. Goossens LM, Nivens MC, Sachs P, et al. Is the EQ-5D responsive to recovery from a moderate COPD exacerbation? Respir Med 2011 Aug; 105 (8): 1195-202

98. Garcia-Rio F, Soriano JB, Miravitlles M, et al. Overdiagnosing subjects with COPD using the 0.7 fixed ratio: correlation with a poor health-related quality of life. Chest 2011 May; 139 (5): 1072-80

99. Kopec JA, Willison KD. A comparative review of four preference-weighted measures of health-related quality of life. J Clin Epidemiol 2003 Apr; 56 (4): 317-25

100. Ringbaek T, Brondum E, Martinez G, et al. EuroQoL in assessment of the effect of pulmonary rehabilitation COPD patients. Respir Med 2008 Nov; 102 (11): 1563-7

101. Briggs AH, Glick HA, Lozano-Ortega G, et al. Is treatment with ICS and LABA cost-effective for COPD? Multinational economic analysis of the TORCH study. Eur Respir J 2010 Mar; 35 (3): 532-9

102. Lock K, Wilson K, Murphy D, et al. A cost-effectiveness model of smoking cessation based on a randomised controlled trial of varenicline versus placebo in patients with chronic obstructive pulmonary disease. Expert Opin Pharmacother 2011 Dec; 12 (17): 2613-26

103. Sun SX, Marynchenko M, Banerjee R, et al. Cost-effectiveness analysis of roflumilast/tiotropium therapy versus tiotropium monotherapy for treating severe-to-very severe COPD. J Med Econ 2011; 14 (6): 805-15

104. Zaniolo O, Iannazzo S, Pradelli L, et al. Pharmacoeconomic evaluation of tiotropium bromide in the longterm treatment of chronic obstructive pulmonary disease (COPD) in Italy. Eur J Health Econ 2012; 13 (1): 71-80

105. Mapel DW, Picchi MA, Hurley JS, et al. Utilization in COPD: patient characteristics and diagnostic evaluation. Chest 2000 May; 117 (5 Suppl. 2): 346S-53S

106. Mapel DW, Dedrick D, Davis K. Trends and cardiovascular co-morbidities of COPD patients in the Veterans Administration Medical System, 1991-1999. COPD 2005 Mar; 2 (1): 35-41

107. Lindberg A, Larsson LG, Ronmark E, et al. Co-morbidity in mild-to-moderate COPD: comparison to normal and restrictive lung function. COPD 2011 Dec; 8 (6): 421-8

108. Anthonisen NR, Skeans MA, Wise RA, et al. The effects of a smoking cessation intervention on 14.5-year mortality: a randomized clinical trial. Ann Intern Med 2005 Feb 15; 142 (4): 233-9
109. Calverley PM, Anderson JA, Celli B, et al. Salmeterol and fluticasone propionate and survival in chronic obstructive pulmonary disease. N Engl J Med 2007 Feb 22; 356 (8): 775-89

110. Calverley PM, Anderson JA, Celli B, et al. Cardiovascular events in patients with COPD: TORCH study results. Thorax 2010 Aug; 65 (8): 719-25

111. Jadad AR, To MJ, Emara M, et al. Consideration of multiple chronic diseases in randomized controlled trials. JAMA 2011; 306 (24): 2670-2

112. Celli B, Decramer M, Leimer I, et al. Cardiovascular safety of tiotropium in patients with COPD. Chest 2010 Jan; 137 (1): 20-30

113. Donohue JF, Singh D, Kornmann O, et al. Safety of indacaterol in the treatment of patients with COPD. Int J Chron Obstruct Pulmon Dis 2011; 6: 477-92

114. Worth H, Chung KF, Felser JM, et al. Cardio- and cerebrovascular safety of indacaterol vs formoterol, salmeterol, tiotropium and placebo in COPD. Respir Med 2011 Apr; 105 (4): 571-9

115. McGarvey LP, Magder S, Burkhart D, et al. Cause-specific mortality adjudication in the UPLIFT $^{\circledR}$ COPD trial: findings and recommendations. Respir Med 2012; 106 (4): 515-21

116. McGarvey LP, John M, Anderson JA, et al. Ascertainment of cause-specific mortality in COPD: operations of the TORCH Clinical Endpoint Committee. Thorax 2007 May; 62 (5): 411-5

117. Lin PJ, Shaya FT, Scharf SM. Economic implications of comorbid conditions among Medicaid beneficiaries with COPD. Respir Med 2010 May; 104 (5): 697-704

118. Menzin J, Boulanger L, Marton J, et al. The economic burden of chronic obstructive pulmonary disease (COPD) in a U.S. Medicare population. Respir Med 2008 Sep; 102 (9): 1248-56

119. Mapel DW, McMillan GP, Frost FJ, et al. Predicting the costs of managing patients with chronic obstructive pulmonary disease. Respir Med 2005 Oct; 99 (10): 1325-33

120. Dalal AA, Shah M, Lunacsek O, et al. Clinical and economic burden of patients diagnosed with COPD with comorbid cardiovascular disease. Respir Med 2011 Oct; 105 (10): 1516-22

121. Patel AR, Donaldson GC, Mackay AJ, et al. The impact of ischemic heart disease on symptoms, health status and exacerbations in COPD. Chest 2012 Apr; 141 (4): 851-7

122. Akazawa M, Halpern R, Riedel AA, et al. Economic burden prior to COPD diagnosis: a matched case-control study in the United States. Respir Med 2008 Dec; 102 (12): 1744-52

123. Fletcher $\mathrm{C}$, Peto R. The natural history of chronic airflow obstruction. Br Med J 1977 Jun 25; 1 (6077): 1645-8

124. Agusti A, Vestbo J. Current controversies and future perspectives in chronic obstructive pulmonary disease. Am J Respir Crit Care Med 2011 Sep 1; 184 (5): 507-13

125. Kohansal R, Martinez-Camblor P, Agusti A, et al. The natural history of chronic airflow obstruction revisited: an analysis of the Framingham offspring cohort. Am J Respir Crit Care Med 2009 Jul 1; 180 (1): 3-10

126. Kanner RE, Anthonisen NR, Connett JE. Lower respiratory illnesses promote FEV(1) decline in current smokers 
but not ex-smokers with mild chronic obstructive pulmonary disease: results from the Lung Health Study. Am J Respir Crit Care Med 2001 Aug 1; 164 (3): 358-64

127. Donaldson GC, Seemungal TAR, Bhowmik A, et al. Relationship between exacerbation frequency and lung function decline in chronic obstructive pulmonary disease. Thorax 2002 Oct; 57 (10): 847-52

128. Kerstjens HA, Rijcken B, Schouten JP, et al. Decline of FEV1 by age and smoking status: facts, figures, and fallacies. Thorax 1997 Sep; 52 (9): 820-7

129. Silverman EK. Exacerbations in chronic obstructive pulmonary disease: do they contribute to disease progression? Proc Am Thorac Soc 2007 Dec; 4 (8): 586-90

130. Celli BR. Predictors of mortality in COPD. Respir Med 2010 Jun; 104 (6): 773-9

131. Cooper K, Brailsford SC, Davies R. Choice of modelling technique for evaluating health care interventions. J Oper Res Soc 2007 Feb; 58 (2): 168-76

132. Brennan A, Chick SE, Davies R. A taxonomy of model structures for economic evaluation of health technologies. Health Econ 2006 Dec; 15 (12): 1295-310

133. Caro JJ, Moller J, Getsios D. Discrete event simulation: the preferred technique for health economic evaluations? Value Health 2010 Dec; 13 (8): 1056-60

134. Pichon-Riviere A, Augustovski F, Bardach A, et al. Development and validation of a microsimulation economic model to evaluate the disease burden associated with smoking and the cost-effectiveness of tobacco control interventions in Latin America. Value Health 2011 Jul-Aug; 14 (5 Suppl. 1): S51-9

135. Mullahy J. Econometric modeling of health care costs and expenditures: a survey of analytical issues and related policy considerations. Med Care 2009 Jul; 47 (7 Suppl. 1): S104-8

136. Marshall DA, Hux M. Design and analysis issues for economic analysis alongside clinical trials. Med Care 2009 Jul; 47 (7 Suppl. 1): S14-20

137. Najafzadeh M, Marra CA, Sadatsafavi M, et al. Cost effectiveness of therapy with combinations of long acting bronchodilators and inhaled steroids for treatment of COPD. Thorax 2008 Nov; 63 (11): 962-7

138. Aaron SD, Vandemheen KL, Fergusson D, et al. Tiotropium in combination with placebo, salmeterol, or fluticasone-salmeterol for treatment of chronic obstructive pulmonary disease: a randomized trial. Ann Intern Med 2007 Apr 17; 146 (8): 545-55

139. Celli BR. Chronic obstructive pulmonary disease: from unjustified nihilism to evidence-based optimism. Proc Am Thorac Soc 2006; 3 (1): 58-65

Correspondence: Dr Douglas W. Mapel, Lovelace Clinic Foundation, 2309 Renard Place SE \#103, Albuquerque, NM 87106-4264, USA

E-mail: DMapel@comcast.net 